\title{
Genotypic Analysis of Respiratory Mucous Sulfation Defects in Cystic Fibrosis
}

\author{
Yulong Zhang, ${ }^{*}$ Benjamin Doranz, ${ }^{*}$ James R. Yankaskas, ${ }^{\boldsymbol{\varsigma}}$ and John F. Engelhardt ${ }^{\star \neq}$ \\ * Department of Molecular and Cellular Engineering, University of Pennsylvania Medical Center, Philadelphia, Pennsylvania 19104; \\ ${ }^{\ddagger}$ Wistar Institute, Philadelphia, Pennsylvania 19104; and ${ }^{\S}$ University of North Carolina at Chapel Hill, North Carolina 27514
}

\begin{abstract}
Intracellular dysfunction of the cystic fibrosis transmembrane conductance regulator (CFTR) has been proposed to alter endosomal acidification. The most widely studied consequence of this defect has been alterations in the biochemical properties of cystic fibrosis (CF) respiratory mucus glycoproteins. However, studies confirming the existence of mucous processing defects in CF have been hindered by the lack of in vivo animal models by which to test these hypotheses in the absence of secondary effects of chronic bacterial infection. The human bronchial xenograft model has been useful in evaluating the pathophysiologic differences between CF and non-CF airway epithelium, in the absence of secondary disease effects such as goblet cell hyperplasia. In this study we sought to compare the extent of sulfation within secreted mucus glycoproteins from CF and non-CF human bronchial xenografts. Cumulative results of xenografts generated from 13 independent CF tissue samples demonstrated a statistically significant higher level of sulfation $(1.7 \pm 0.18, P<0.026)$ as compared to non-CF paired controls. Such findings add to the growing body of knowledge that primary defects in sulfation exist in CF respiratory mucin. Correlation of genotype with the extent of mucus sulfation revealed two categories of CF tissues with statistically different mucus sulfation profiles. Results from these studies demonstrated a $2.0 \pm 0.15$-fold higher level of mucus sulfation produced from xenografts of five defined CF genotypes as compared to non-CF controls $(P<0.004$, $n=10)$. Interestingly, three CF samples for which one mutant allele remained undefined ( $\Delta F 508$ /unknown or G551D/unknown) demonstrated no statistical difference in the level of sulfation as compared with matched non-CF controls $(n=3)$. This as yet unknown allele was not identified within a screen for the 26 most common CF mutations. These results provide preliminary evidence for allelic variation within the CF population which may begin to elucidate
\end{abstract}

Address correspondence to John F. Engelhardt, Institute for Human Gene Therapy, Department of Molecular and Cellular Engineering, University of Pennsylvania Medical Center, Room 305, BRB1, Philadelphia, Pennsylvania 19104. Phone: 215-898-6638; FAX: 215-573-8590.

Received for publication 6 April 1995 and accepted in revised form 29 August 1995.

J. Clin. Invest.

(C) The American Society for Clinical Investigation, Inc.

0021-9738/95/12/2997/08 \$2.00

Volume 96, December 1995, 2997-3004 the structure-function of CFTR with regards to intracellular mucus processing defects. (J. Clin. Invest. 1995. 96:29973004.) Key words: cystic fibrosis • pathophysiology • mucus - airway epithelium

\section{Introduction}

Cystic fibrosis $(\mathrm{CF})^{1}$ is a lethal inherited disease caused by abnormalities in epithelial cell function $(1,2)$. Patients usually die of respiratory failure due to recurrent and destructive pneumonia. The primary cellular abnormality in the lung is believed to reside in the epithelium of the airways and submucosal glands. Isolation of the gene responsible for $\mathrm{CF}$ has provided insight into the molecular basis of the disease $(3,4,5)$. Ongoing progress in the development of effective gene therapies for $\mathrm{CF}$ have shown tremendous promise. Despite successes in the ability to transfer the cystic fibrosis transmembrane conductance regulator (CFTR) gene to lungs of animals models $(6,7,8)$ and the recent initiative of phase I clinical trials $(9,10,11)$, little is known about the underlying pathophysiologic mechanisms which lead to the development of chronic bacterial infections and unavoidable morbidity of this lung disease. The identification of functionally relevant endpoints for evaluating the effectiveness of gene therapy approaches will aid in the development these therapeutic strategies.

Current hypotheses of the pathophysiologic mechanisms which lead to the unusually thick mucus in $\mathrm{CF}$ and chronic Pseudomonas infections are based primarily on the notion that CF respiratory epithelia have defective chloride secretion and elevated sodium absorption (12-15). Although the molecular etiology of defective chloride secretion is known to be due to lack of CFTR channel activity, mechanisms by which $\mathrm{Na}$ absorption is elevated remain obscure. These alterations in electrolyte transport are thought to create a milieu for bacterial infection by decreasing epithelial fluid secretion which in turn leads to improper hydration of mucus at the epithelial surface, poor mucociliary clearance, and ultimately bacterial colonization $(1,16)$. In addition to the contribution of electrolyte transport, several other findings have suggested that primary defects in mucous sulfation, sialylation, and/or glycosylation may also contribute to the predisposition of bacterial colonization in the CF lung (17-20). These findings suggest, that in addition to apical chloride channel function, CFTR may also play an intracellular role in the processing of glycoproteins. Several studies have supported the notion that CFTR may act as an intracellular

1. Abbreviations used in this paper: CF, cystic fibrosis; CFTR, cystic fibrosis transmembrane regulator. 
chloride channel which regulates anion transport, in conjunction with an ATP driven proton pump, to acidify endosomal compartments $(21,22)$. These studies which analyzed the intravesicular $\mathrm{pH}$ of golgi compartments have demonstrated a higher $\mathrm{pH}$ in $\mathrm{CF}$ as compared with non-CF cells. Such defects in golgi $\mathrm{pH}$ have been proposed to effect processing of glycoproteins by shifting the $\mathrm{pH}$ of this compartment and decreasing the activity of modifying enzymes such as sialyltransferase. Other studies evaluating the effects of defective CFTR on endosomal recycling also support the notion that, in addition to functioning at the apical membrane, CFTR also plays an important role as an intracellular chloride channel $(23,24)$.

Previous studies have attempted to evaluate the pathophysiologic contribution CFTR may play as an intracellular chloride channel by analyzing biochemical defects in CF mucus (2527). Two approaches have been traditionally used for this analysis including: $(a)$ the purification and fractionation of mucus from CF and non-CF patients followed by analysis of sulfate, sialic acid, and carbohydrate composition $(26,27)$ and $(b)$ the purification and fractionation of radiolabeled mucus glycoproteins from CF and non-CF primary nasal or tracheal explants $(26,28)$. Because of the complexity of mucus glycoprotein modifications which accompany bacterial infection, disease controls have been used in these studies to minimize the extent of secondary effects. However, due to the unique nature of bacterial infection in $\mathrm{CF}$, secondary changes in mucous biochemistry may likely differ from those found in diseased controls such as chronic bronchitis. Researchers have attempted to address this potential complication by in vitro analysis of nasal and tracheal primary explants which have been removed from the infectious milieu. However, even in the absence of active bacterial infection in primary explants, this experimental design also provides limitations due to the effects of surface epithelial cell remodeling (i.e., goblet cell hyperplasia) which likely persist in culture. Hence, in the absence of a genetic CF model not complicated by bacterial infection or surface airway remodeling, the elucidation of primary defects in mucus remain controversial (29) as indicated by reports which show no abnormalities in the biochemical properties CF mucus (30).

A uniquely suited model of the human CF and non-CF airway epithelium called human bronchial xenografts has been previously described $(7,31,33)$. In this model system, a fully differentiated epithelium is generated from primary cultures of human bronchial airway epithelial cells seeded onto denuded rat tracheas and transplanted into athymic mice. The ability to reconstitute a fully differentiated epithelium from cultured progenitor cells has allowed for the reconstruction of more pristine $\mathrm{CF}$ airways free from secondary effects of bacterial infection. Recently, in vivo electrophysiologic evaluation of this model system has characterized defects in chloride and $\mathrm{Na}$ transport which are indicative of those seen in native CF nasal epithelium (32). Using the human bronchial xenograft model, this report attempts to evaluate the existence of sulfation defects in respiratory mucus glycoproteins from seven different CF genotypes. We compared the sulfation patterns of radiolabeled large molecular weight mucin purified from thirteen CF and non-CF paired human bronchial xenografts. This model system has allowed for a more physiologic evaluation of primary defects in CF mucous biochemistry which are free from secondary effects of airway remodeling due to chronic bacterial infection.

\section{Methods}

Generation of $C F$ and non-CF human bronchial primary cell cultures and xenograft airways. Human bronchial xenografts were generated from proximal bronchial tissue harvested from donor (non-CF) and recipient $(\mathrm{CF})$ lungs at the time of transplantation. $13 \mathrm{CF}$ and non-CF paired tissues were analyzed. The $\mathrm{CF}$ genotypes analyzed in this study included $\Delta \mathrm{F} 508 / \Delta \mathrm{F} 508(4) ; \Delta \mathrm{F} 508 / 1717-1 \mathrm{G} \rightarrow \mathrm{A}(2) ; \Delta \mathrm{F} 508 /$ $621+1 \mathrm{G} \rightarrow \mathrm{T}(2) ;$ G542X/G551D (1); $\Delta \mathrm{F} 508 / \mathrm{G} 542 \mathrm{X}(1) ; \Delta \mathrm{F} 508 /$ unknown (2); and G551D/unknown (1). The unknown CF alleles are defined as the absence of the following 26 common mutations: G85E, R117H, 621+1G > T, R334W, R347C, R347P, R347H, S492F, Q493R, 1609delCA, $\Delta 1507, \Delta$ F508, 1717-1G>A, G542X, S549I, S549N, S549R(A >C), G551D, R553X, R506T, R1162X, S1251N, W1282X, R1283M, R1283K, and N1303K. This panel of mutations has detected $87 \%$ of $301 \mathrm{CF}$ chromosomes analyzed from the University of Pennsylvania Molecular Diagnostic laboratory. Of the 13 non-CF patients genotyped, one was heterozygous for the $\Delta \mathrm{F} 508$ mutation. Primary cultures of bronchial airway epithelial cells were prepared according to a previous protocol with modifications (31). Modifications in this protocol were adopted to grow cells within a commercially available media (BGEM; Clonetics Corp., San Diego, CA) which allows for the growth of primary cells with basal cell characteristics (i.e., cytokeratin-14 positive by immunocytochemistry, data not shown). We felt that these alteration would provide more homogeneous cultures from $\mathrm{CF}$ and nonCF tissues and minimize the secondary effects carried over to primary culture (i.e., the percentage of goblet cells). Additionally, culture medium contained $80 \mu \mathrm{g} / \mathrm{ml}$ tobramycin, $100 \mu \mathrm{g} / \mathrm{ml}$ ceftazidime, $100 \mu \mathrm{g} /$ $\mathrm{ml}$ imepenam/cilastatin, and $2.5 \mu \mathrm{g} / \mathrm{ml}$ amphotericin B to control bacterial and yeast infections. Cultures were propagated by two techniques including explant growth (12-20 d in culture) and proteinase released primary cells ( $4-7 \mathrm{~d}$ in culture). Both techniques provide similar results with respect to the airway reconstitution of xenografts (data not shown). Cultures were harvested by treatment of $0.1 \%$ trypsin followed by the addition of $10 \%$ FCS/Ham's F12. Cells were pelleted and resuspended in hormonally defined medium for seeding into denuded rat tracheas generated by freeze thawing and irrigation three times. Denuded rat tracheas are devoid of any viable airway epithelium and do not reconstitute an epithelium when transplanted without seeded primary cells (data not shown). Tracheas were ligated to flexible tubing at both ends after seeding of $2 \times 10^{6}$ primary bronchial epithelial cells in $30 \mu \mathrm{l}$ of hormonally defined medium. Xenografts were implanted in pairs (one non-CF and one CF) subcutaneously in the flanks of male nu/nu Balb/c mice such that the ends of the tubing passed through the skin and were easily accessible for flushing and harvesting of mucus. Xenografts were flushed biweekly with Ham's F12 to remove excess mucus and other secreted proteins. By week 3-4, grafts develop a fully differentiated mucociliary epithelium. Mucin secreted from xenografts was metabolically labeled as described below between 4 and $5 \mathrm{wk}$ after transplantation.

Frequency of goblet cells in $C F$ and non-CF xenografts. The percentage of goblet cells was evaluated by quantitating the number of alcian blue positively stained cells in eight xenografts from four independent genotypes of $\mathrm{CF}$ and non-CF paired xenografts. A total of $>5000$ airway epithelial cells were screened from each xenograft to determine the frequency of alcian blue positive goblet cells. Statistical comparisons were performed using both paired and unpaired Student's $t$ tests.

Isolation of metabolically labeled mucus glycoprotein from xenografts. Fully differentiated bronchial xenografts were metabolically labeled with both $\mathrm{Na}_{2} \mathrm{~S}^{35} \mathrm{O}_{4}(25 \mu \mathrm{Ci})$ and $\left[{ }^{3} \mathrm{H}\right]$ glucosamine $(25 \mu \mathrm{Ci})$ for $72 \mathrm{~h}$ by instillation of radioisotope in Hepes-buffered phosphate ringers (HPBR) solution. Metabolically labeled crude secretions were harvested by irrigation with $1 \mathrm{ml}$ of HPBR and frozen in dry ice. All analyses were performed from paired CF and non-CF xenografts implanted in the same mouse. Crude mucus secretions were purified by two rounds of gel filtration by modifications of a previously described protocol (26, 28). Xenograft secretions were reduced and denatured by dialysis against $10 \mathrm{mM}$ Tris $\mathrm{pH} 8.0,5 \mathrm{mM}$ DTT, and $8 \mathrm{M}$ urea for $24 \mathrm{~h}$ followed 
by fractionation in the same buffer on a sepharose CL-6B column (1 $\times 60 \mathrm{~cm})$ at a flow rate of $1.5 \mathrm{ml} / \mathrm{h}$. The void volume peaks were pooled, carboxymethylated under nitrogen with $15 \mathrm{mM}$ iodoacetamide $\mathrm{pH} 9.0$ for $45 \mathrm{~min}$ at $25^{\circ} \mathrm{C}$ followed by extensive dialysis against 10 $\mathrm{mM}$ Tris pH 7.5, $50 \mathrm{mM} \mathrm{NaCl}, 1 \mathrm{mM}$ PMSF for $48 \mathrm{~h}$. Dialyzed sample was mixed with concentrated stocks of NaAcetate, $\mathrm{MgCl}_{2}$, and PMSF to a final concentration of $0.1 \mathrm{M} \mathrm{NaAcetate} \mathrm{pH} 5.0,3 \mathrm{mM} \mathrm{MgCl}_{2}, 1$ $\mathrm{mM}$ PMSF before digestion with $240 \mathrm{U} / \mathrm{ml}$ DNase and $75 \mathrm{U} / \mathrm{ml}$ of bovine testicular hyaluronidase (Type VI; Sigma Chemical Co., St. Louis, MO) for $6 \mathrm{~h}$ at $37^{\circ} \mathrm{C}$. This fraction was then dialyzed against 10 $\mathrm{mM}$ Tris $\mathrm{pH} 8.0,5 \mathrm{mM}$ DTT, and $8 \mathrm{M}$ urea for $24 \mathrm{~h}$ followed by centrifugation in a centricon-30. These concentrated samples $(500 \mu \mathrm{l})$ were loaded onto a second gel filtration Sepharose CL-6B column (2 $\times 125 \mathrm{~cm}$ ) at a flow rate of $3 \mathrm{ml} / \mathrm{h}$. Void volume peaks included hyaluronidase insensitive mucus glycoprotein.

Additional enzymatic digestions of twice column purified hyaluronidase insensitive large molecular mucin were performed with Chondroitin $\mathrm{ABC}$ lyase and Heparin Lyase II to confirm the absence of sulfated glycosaminoglycans in purified mucin fractions. Digestions with Chondroitin $A B C$ lyase were performed by dialysis of purified mucin peaks IIa against $0.1 \mathrm{M}$ Tris acetate buffer, $\mathrm{pH} 7.3$ at $4^{\circ} \mathrm{C}$ followed by digestion with $1 \mathrm{U} / \mathrm{ml}$ with Chondroitin $\mathrm{ABC}$ lyase (Sigma Chemical Co.) for $18 \mathrm{~h}$ at $37^{\circ} \mathrm{C}$. Similarly digestion with Heparin lyase II (Sigma Chemical Co.) were performed by dialysis of purified mucin peaks IIa against 0.1 $\mathrm{M} \mathrm{K}_{2} \mathrm{HPO}_{4}, 1 \mathrm{mM} \mathrm{CaCl}_{2}, \mathrm{pH} 7.0$ buffer at $4^{\circ} \mathrm{C}$ followed by digestion with $1 \mathrm{U} / \mathrm{ml}$ Heparin lyase II for $18 \mathrm{~h}$ at $43^{\circ} \mathrm{C}$. Digested mucin samples were then dialyzed against $10 \mathrm{mM}$ Tris $\mathrm{pH} 8.0,5 \mathrm{mM}$ DTT, $8 \mathrm{M}$ urea buffer and refractionated by CL-6B column chromatography. The percentage of $\left[{ }^{3} \mathrm{H}\right]$ glucosamine and $\mathrm{S}^{35} \mathrm{O}_{4}$ in the void and included volume fractions were compared with that of control samples digested in the absence of enzyme. Since pilot studies with CF and non-CF samples demonstrated the no change in the void volume elution profile or the $\mathrm{S}^{35} \mathrm{O}_{4} /\left[{ }^{3} \mathrm{H}\right]$ glucosamine ratios of purified mucin fractions, these digestions were not incorporated into the general purification scheme used to analyze samples in this report.

Statistical analysis comparing the extent of sulfation between CF and non-CF xenografts was performed using the Student's $t$ test. Because of variability in the absolute ${ }^{35} \mathrm{~S}$ and $\left[{ }^{3} \mathrm{H}\right]$ glucosamine labeling efficiency between independent experiments performed on different days, all comparisons were performed by a paired analysis of the raw ${ }^{35} \mathrm{~S} /$ $\left[{ }^{3} \mathrm{H}\right]$ glucosamine ratios between $\mathrm{CF}$ and non-CF samples grafted in the same mouse. Statistical significance denotes a $P<0.05$.

Lectin binding studies to determine relative mannose and sialic acid content. To confirm that purified mucin pools were separated from mannose rich contaminating glycoproteins, we analyzed purified mucus fractions for the extent of lectin specific binding to sialic acid and mannose. Various fractions from the mucus glycoprotein purification were normalized to 1000 total dpm of $\left[{ }^{3} \mathrm{H}\right]$ glucosamine label and slot blotted onto nitrocellulose. After blocking of nitrocellulose filters with a $1 \%$ lectin blocking solution (B \& $\mathrm{M}$ ) in $50 \mathrm{mM}$ Tris $\mathrm{pH} 7.5$ overnight at $4^{\circ} \mathrm{C}$, filters were probed with peroxidase-LFA lectin (for the detection of sialic acid) or peroxidase-GNA lectin (for the detection of mannose) for $4 \mathrm{~h}$ at room temp. Filters were then washed four times in $50 \mathrm{mM}$ Tris $\mathrm{pH} 7.5$ and reacted with DAB substrate to visualize peroxidase bound lectin. Typical reaction times were between 2-10 min. Purified mucus glycoprotein standard (isolated from bovine submandibular gland; Sigma Chemical Co.) was used to relate the intensity of staining to known microgram quantities of mucus glycoprotein.

\section{Results}

Expansion of airway progenitor cell in vitro removes secondary effects of goblet cell hyperplasia in CF xenografts. The generation of in vivo bronchial xenograft airways from both CF and non-CF tissues provides the unique opportunity to assess the biochemical differences in secreted mucin from fully differenti- ated airways. Since, previous studies evaluating secreted mucin in CF airway explants have been hindered by secondary effects of airway remodeling in the presence of bacterial infection, we sought to generate a more pristine CF airway free from goblet cell hyperplasia. We hypothesized that transplantation of bacterial free cultured primary cells would allow for expansion of airway progenitor cells and generation of CF airways with a normal abundance of goblet cells. To this end we evaluated the abundance of goblet cells in CF and non-CF xenografts by alcian blue histochemical staining. These studies demonstrated no statistical differences in the abundance of alcian blue positive goblet cells in four CF $(3.2 \pm 1.3 \%)$ and non-CF $(3.6 \pm 1.2 \%)$ paired xenografts analyzed. These $\mathrm{CF}$ airways will provide a more physiologic comparison to non-CF airways by which to base conclusions regarding primary defects in secreted mucin.

Purification and characterization of large molecular weight mucus glycoprotein from xenografts. Purified large molecular weight metabolically labeled mucin was analyzed from xenografts generated with 13 paired $\mathrm{CF}$ and non-CF bronchial tissues. $\mathrm{CF}$ and non-CF-paired xenografts implanted within the same mouse were simultaneously labeled with a mixture of $\mathrm{Na}_{2} \mathrm{~S}^{35} \mathrm{O}_{4}$ and $\left[{ }^{3} \mathrm{H}\right]$ glucosamine and secretions collected by irrigation. Crude secretions were purified through two rounds of gel filtration which included digestion with hyaluronidase. Additional studies evaluating the resistance of twice gel-filtration purified mucin to Chondroitin $\mathrm{ABC}$ lyase and Heparin lyase II demonstrate that Heparin/Heparan sulfate and Chondroitin/ Dermatan sulfate molecules are absent or minor contaminants in these fractions (data not shown). Resistance of purified mucin fractions to these enzymes was determined by the lack of movement of radioactivity from the void volume to the included volume peak using a third gel-filtration column after digestion. Removal of contaminant proteoglycans and N-linked oligosaccharides from mucin samples purified through a single round of gel filtration was documented by two criteria including: $(a)$ the digestion of void volume large molecular weight glycoprotein fractions with hyaluronidase followed by fractionation of a small molecular weight peak on a second gel-filtration column, and $(b)$ the removal of mannose binding lectin (GNA) material from void volume peaks after reduction/carboxymethylation and subsequent elution in the included volume peaks on a second gel-filtration column.

Fig. 1 demonstrates the typical gel-filtration elution profile of radiolabeled mucin from a $\mathrm{CF}$ and non- $\mathrm{CF}$-paired sample. The removal contaminant non-sulfated $\left[{ }^{3} \mathrm{H}\right.$ ] glucosamine-labeled molecules (likely proteoglycans) appears as smaller molecular weight peak (peak IIb, Fig. 1, $C$ and $D$ ) after hyaluronidase treatment of void volume fractions (Fig. 1, $A$ and $B$, peak Ia) from the first round of gel filtration. These studies have reproduced the typical purification schemes of large molecular weight mucus previously reported $(25,26,28)$. Lectins were also used to document the purification profile of mucin by evaluating sialic acid (LFA lectin) and mannose (GNA lectin) binding. In these studies normalized dpm quantities of $\left[{ }^{3} \mathrm{H}\right]-$ glucosamine-labeled mucus glycoprotein were slotted onto nitrocellulose and the filters probed with peroxidase-labeled LFA- or GNA-labeled lectin. Filters were developed with DAB and the intensity of the reaction products used to infer the extent of lectin binding. To evaluate the purification of large molecular weight mucin, the intensity of LFA lectin binding was compared with that of GNA for four fractions within the purification; $(a)$ 

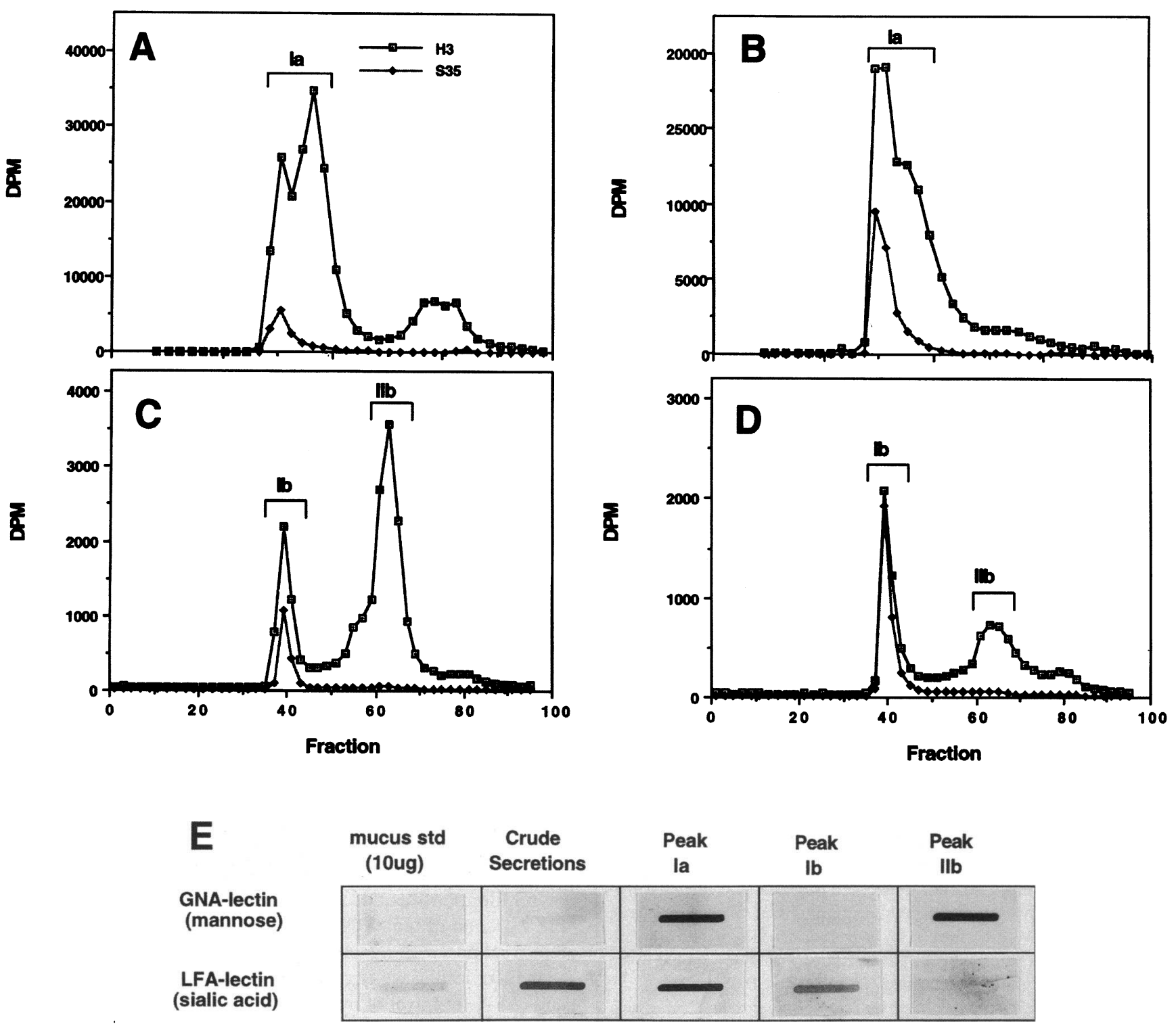

Figure 1. Purification of large molecular weight mucus glycoproteins by gel filtration. Paired $\mathrm{CF}$ and non-CF xenografts grafted within the same mouse were metabolically labeled with $25 \mu \mathrm{Ci}$ of both $\mathrm{Na}_{2} \mathrm{~S}^{35} \mathrm{O}_{4}$ and $\left[{ }^{3} \mathrm{H}\right]$ glucosamine for $72 \mathrm{hr}$ and the radiolabeled secretions collected by irrigation. Crude secretions were denatured in $8 \mathrm{M}$ urea/DDT and eluted on a Sepharose CL-6B gel-filtration column $(A$, non-CF; $B, C F)$. Void volume fractions $(\mathrm{Ia}$ ) were pooled, carboxymethylated, and digested with hyaluronidase and DNase. Hyaluronidase treated fractions were concentrated to $500 \mu \mathrm{l}$ and purified through a second round of gel-filtration $(C$, non-CF; $D, C F)$. Void volume hyaluronidase insensitive fraction $(I b)$ and hyaluronidase sensitive fractions (Ilb) were pooled for analysis. Comparisons of ${ }^{35} \mathrm{~S} /{ }^{3} \mathrm{H}$ ratios were performed on fraction Ib. Samples at various steps of the purification were compared for the extent of mannose and sialic acid content by lectin binding studies $(E)$. In these studies peroxidase linked lectins GNA (mannose binding) and LFA (sialic acid binding) were bound to $1000 \mathrm{dpm}$ of the various fractions from a representative nonCF sample slotted onto nitrocellulose filters. Crude secretions represent the starting material denatured in $8 \mathrm{M}$ Urea/DDT. Pooled fractions (Ia) were treated with hyaluronidase before lectin binding studies. Fractions $\mathrm{Ib}$ and Ilb were used directly following gel-filtration column chromatography. Purified bovine submandibular gland mucus standard was purchased from Sigma Chemical Co. Results demonstrate the separation of mannose containing glycoproteins (peak IIb) from hyaluronidase insensitive large molecular weight mucin, (peak Ib).

crude secretions in $8 \mathrm{M}$ urea; $(b)$ the first gel-filtration void volume peak (including all large molecular weight glycoproteins, peak Ia); (c) the second gel-filtration void volume peak (including hyaluronidase insensitive large molecular weight glycoproteins, peak $\mathrm{Ib})$; and $(d)$ the inclusion volume peak from the second gel-filtration column (including hyaluronidase sensitive small molecular weight glycoprotein fragments, peak IIb). Fig. 1 shows a typical lectin binding profile of fractions of this purification scheme. These data demonstrate the increase in LFA binding with successive purification steps and the disappearance of GNA (mannose) binding lectin from the void volume peaks after carboxymethylation and hyaluronidase treatment. These results provide evidence that both proteoglycan and $\mathrm{N}$-linked mannose containing oligosaccharide contaminants were effectively removed by our purification strategy.

The molecular weight of purified large molecular weight 


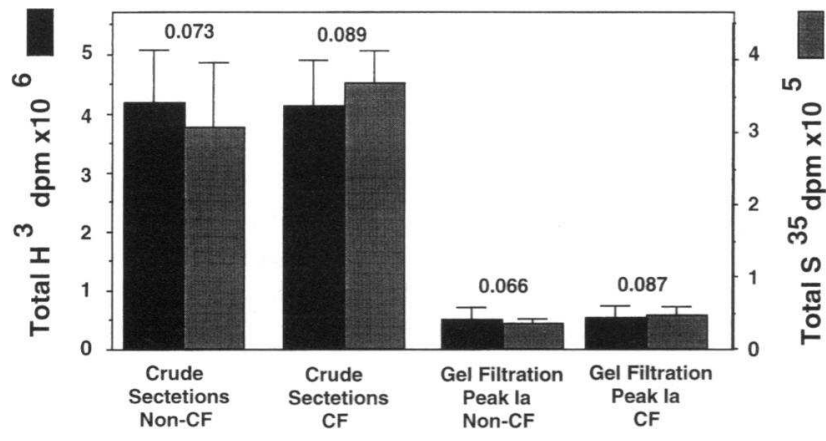

Figure 2. Quantitation of $\left[{ }^{3} \mathrm{H}\right]$ glucosamine and $\mathrm{S}^{35} \mathrm{O}_{4}$ incorporation in crude total secreted proteins and large molecular weight crude glycoproteins. To evaluate whether the total uptake of $\left[{ }^{3} \mathrm{H}\right]$ glucosamine and $\mathrm{S}^{35} \mathrm{O}_{4}$ molecules may be responsible for alteration in the extent of mucus sulfation in CF airway epithelium, we quantitated the total radioactivity in both crude urea dialyzed secretions and crude large molecular weight void volume fractions from the first gel-filtration column (fraction Ia, see Fig. 1). The graph shows the mean \pm SEM total dpms for each fraction harvested from 13 independent $\mathrm{CF}$ and non-CF paired xenografts. The left axis gives the total $\left[{ }^{3} \mathrm{H}\right]$ glucosamine dpms while the right axis gives the total $\mathrm{S}^{35} \mathrm{O}_{4}$ dpms. For comparison with purified hyaluronidase treated large molecular weight mucin fractions given in Fig. 3, the average ratio of $\mathrm{S}^{35} \mathrm{O}_{4}$ to $\left[{ }^{3} \mathrm{H}\right]$ glucosamine counts are given above each group.

hyaluronidase insensitive mucus glycoprotein was determined by gel-filtration with co-eluted molecular weight standards ( $\mathrm{Bi}$ oRad Inc., Richmond, CA; myoglobin, 17 kD; ovalbumin, 44 $\mathrm{kD}$; gamma globulin, $158 \mathrm{kD}$; thyroglobulin, $670 \mathrm{kD}$; and protein aggregates in excess of $5000 \mathrm{kD}$ ). These results demonstrated a linear fractionation of molecular weight markers and a co-elution of radioactivity of purified mucus glycoprotein with large protein aggregate markers in excess of $5000 \mathrm{kD}$ (data not shown). From these studies we can conclude that the conditions used for gel-filtration purification in this study isolate mucin in excess of 5 million dalton molecular weight.

To address whether alterations in the extent of sulfation may be due to variable uptake of radiolabeled precursors $\mathrm{Na}_{2} \mathrm{~S}^{35} \mathrm{O}_{4}$ or $\left[{ }^{3} \mathrm{H}\right]$ glucosamine between $\mathrm{CF}$ and non-CF epithelium, we assessed the total ${ }^{35} \mathrm{~S}$ and ${ }^{3} \mathrm{H}$ dpm counts in both crude urea dialyzed total secretions and partially purified large molecular weight glycoproteins from the first gel-filtration column (peak Ia, see Fig. 1). Results from this analysis are presented in Fig. 2 and demonstrate no significant differences in the total incorporation of $\left[{ }^{3} \mathrm{H}\right]$ glucosamine within either crude or peak Ia fractions between CF and non-CF. Furthermore, although the $\left[{ }^{3} \mathrm{H}\right]$ glucosamine normalized level of ${ }^{35} \mathrm{~S}$ incorporation tended to be higher for CF xenografts (1.2-fold for crude secretions, and 1.3-fold for peak Ia), the extent of this increase was less than that seen following hyaluronidase treatment (results discussed below). These findings suggest that alterations in the extent of $\left[{ }^{3} \mathrm{H}\right]$ glucosamine uptake do not confound analyses which normalize the extent of sulfation to $\left[{ }^{3} \mathrm{H}\right]$ glucosamine incorporation.

Sulfate content of mucus glycoprotein from $C F$ and non$C F$ xenografts. To avoid differences in the specific activity of radiolabeled precursor and variability in the extent of precursor incorporation between experiments, only matched xenografts ( $\mathrm{CF}$ vs non-CF) within the same mouse were compared. We

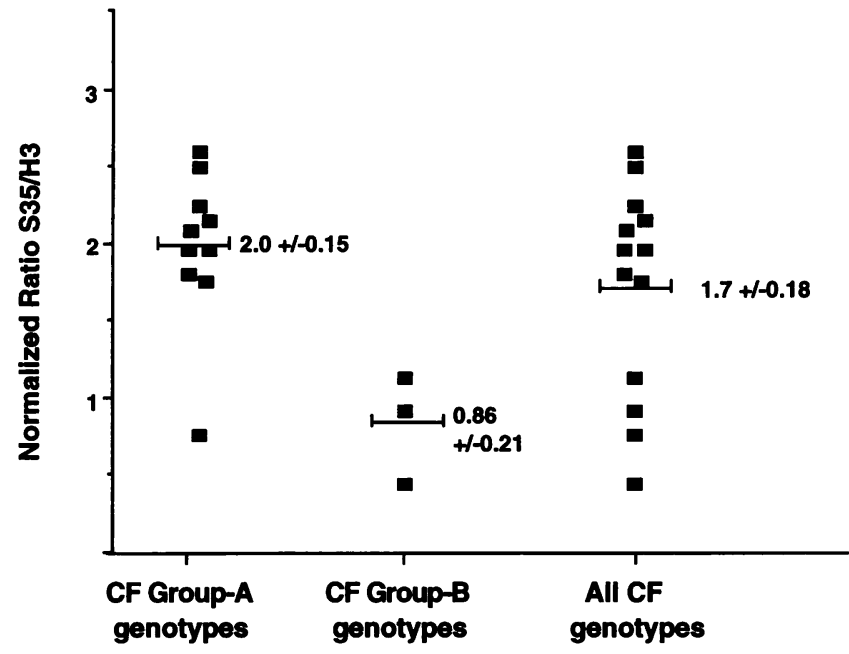

Figure 3. Radiolabeled sulfur content of purified hyaluronidase insensitive large molecular weight mucus glycoprotein from CF and non-CF xenografts. The ${ }^{35} \mathrm{~S} /\left[{ }^{3} \mathrm{H}\right]$ glucosamine ratio of purified large molecular weight mucus glycoprotein was compared from xenografts generated from 13 independent CF and non-CF paired tissues. When duplicate xenografts were performed from one set of tissue samples, the raw ${ }^{35} \mathrm{~S} /$ $\left[{ }^{3} \mathrm{H}\right]$ glucosamine ratios were averaged. For presentation, the ${ }^{35} \mathrm{~S} /\left[{ }^{3} \mathrm{H}\right]-$ glucosamine ratio was normalized for each pair of $\mathrm{CF}$ and non-CF xenografts such that the non-CF sample was made equal to one. This was necessary due to variability in the absolute labeling efficiency between experiments performed on different days. This was in part due to variability in the specific activity of $\mathrm{Na}_{2} \mathrm{~S}^{35} \mathrm{O}_{4}$ and $\left[{ }^{3} \mathrm{H}\right]$ glucosamine precursor from different lots. The cumulative data is presented from all $\mathrm{CF}$ and non-CF paired samples with two subdivided CF categories based on genotype (group-A, known genotype on both alleles [a listing of individual genotypes and normalized ${ }^{35} \mathrm{~S} /\left[{ }^{3} \mathrm{H}\right]$ glucosamine ratios are given in Table I]; group-B, partially defined genotypes including two patients with $\Delta F 508 /$ unknown and one patient with G551D/unknown genotypes). Groups were analyzed for statistically significant differences by a paired analysis of the raw ${ }^{35} \mathrm{~S} /\left[{ }^{3} \mathrm{H}\right]$ glucosamine ratios using Student's $t$ test. The following p-values were obtained: $(a)$ all CF samples vs non-CF, $P<0.026, n=13$; $(b)$ CF group-A vs non-CF, $P$ $<0.004, n=10$; (c) CF group-B vs non-CF, $P>0.95, n=3$.

compared the sulfation ratios between $\mathrm{CF}$ and non-CF purified large molecular weight, hyaluronidase insensitive, mucus glycoprotein by several criteria. All statistical comparisons were performed by a paired Student's $t$ test analysis of the raw ${ }^{35} \mathrm{~S} /$ $\left[{ }^{3} \mathrm{H}\right]$ glucosamine ratios. When ${ }^{35} \mathrm{~S} /\left[{ }^{3} \mathrm{H}\right]$ glucosamine ratios were compared between all $\mathrm{CF}$ and non-CF samples the mean increase in sulfation was $1.7 \pm 0.18$-fold higher $(P<0.026, n$ $=13$ ) in $\mathrm{CF}$ as compared with non-CF samples (Fig. 3 and Table I). However, when the genotypes of the various CF samples were tabulated, two categories emerged which showed differences in their sulfation profile. The first of these categories involved CF samples with definable genotypes $[\Delta \mathrm{F} 508 / \Delta \mathrm{F} 508$ $(n=4) ; \Delta \mathrm{F} 508 / 1717(n=2) ; \Delta \mathrm{F} 508 / 621(n=2) ; \mathrm{G} 542 \mathrm{X} /$ G551D $(n=1) ; \Delta$ F508/G542X $(n=1)]$ which showed a $2.0 \pm 0.15$-fold higher ${ }^{35} \mathrm{~S} /\left[{ }^{3} \mathrm{H}\right]$ glucosamine ratio $(P<0.004)$ as compared with non-CF samples (Fig. 3 ). The average raw ${ }^{35} \mathrm{~S} /\left[{ }^{3} \mathrm{H}\right]$ glucosamine ratios for this $\mathrm{CF}$ category was $0.32 \pm 0.07$ as compared with $0.16 \pm 0.04$ for the non-CF samples. When the fold increase in ${ }^{35} \mathrm{~S} /\left[{ }^{3} \mathrm{H}\right]$ glucosamine ratios were compared between these various known $\mathrm{CF}$ genotypes, no statistical differ- 
Table I. CF Patient Clinical Information

\begin{tabular}{|c|c|c|c|c|c|}
\hline Age* & Sex & CF genotype ${ }^{\ddagger}$ & PS/PI & Sweat $\mathrm{Cl}^{\|}$ & ${ }^{35} \mathrm{~S} /\left[{ }^{3} \mathrm{H}\right]$ ratio \\
\hline 37 & $\mathbf{M}$ & $\Delta \mathrm{F} 508 / \Delta \mathrm{F} 508$ & PI & N/A & 2.2 \\
\hline 22 & $\mathbf{M}$ & $\Delta \mathrm{F} 508 / \Delta \mathrm{F} 508$ & PI & 93 & 1.8 \\
\hline 13 & $\mathbf{M}$ & $\Delta \mathrm{F} 508 / \Delta \mathrm{F} 508$ & PI & 117 & 0.78 \\
\hline 24 & $\mathbf{M}$ & $\Delta \mathrm{F} 508 / \Delta \mathrm{F} 508$ & PI & 112 & 2.1 \\
\hline 22 & F & $\Delta \mathrm{F} 508 / 1717-1 \mathrm{G}>\mathrm{A}$ & PI & 120 & 2.0 \\
\hline 34 & F & $\Delta \mathrm{F} 508 / 1717-1 \mathrm{G}>\mathrm{A}$ & PI & 85 & 2.6 \\
\hline 31 & $\mathbf{M}$ & $\Delta$ F508/G542X & PI & 82 & 1.8 \\
\hline 17 & F & G542X/G551D & PI & 93 & 1.9 \\
\hline 27 & $\mathbf{M}$ & $\Delta \mathrm{F} 508 / 621+1 \mathrm{G}>\mathrm{T}$ & PI & 125 & 2.5 \\
\hline 27 & $\mathbf{M}$ & $\Delta \mathrm{F} 508 / 621+1 \mathrm{G}>\mathrm{T}$ & PI & 69 & 2.0 \\
\hline 34 & $\mathrm{~F}$ & $\mathrm{G} 551 \mathrm{D} / ?$ & PI & 108 & 0.46 \\
\hline 34 & $\mathbf{M}$ & $\Delta \mathrm{F} 508 / ?$ & PI & 78 & 1.2 \\
\hline 23 & $\mathbf{M}$ & $\Delta \mathrm{F} 508 / ?$ & PI & 87 & 0.93 \\
\hline
\end{tabular}

* The age at which CF patients underwent lung transplantation. ${ }^{\ddagger}$ Question mark denotes unknown mutant alleles (genotypes screened include G85E, R117H, 621+1G > T, R334W, R347C, R347P, R347H, S492F, Q493R, 1609delCA, $\Delta \mathrm{I} 507, \Delta \mathrm{F} 508,1717-1 \mathrm{G}>\mathrm{A}, \mathrm{G} 542 \mathrm{X}$, S549I, S549N, S549R (A>C), G551D, R553X, R506T, R1162X, S1251N, $\mathrm{W} 1282 \mathrm{X}, \mathrm{R} 1283 \mathrm{M}, \mathrm{R} 1283 \mathrm{~K}$, and N1303K. ${ }^{8} \mathrm{PS}$, pancreatic sufficient; $P I$, pancreatic insufficient. "N/A, sweat chloride not available. "Ratio of ${ }^{35} \mathrm{~S} /\left[{ }^{3} \mathrm{H}\right]$ glucosamine from $\mathrm{CF}$ xenograft purified mucin normalized to paired controlled non-CF mucin.

ences were seen (Fig. 3 and Table I). Surprisingly, a second category of $\mathrm{CF}$ samples with only partially defined genotypes [ $\Delta$ F508/unknown $(n=2)$ and G551D/unknown $(n=1)$ ] showed no statistical difference in the extent of sulfation as compared to their matched non-CF controls (Fig. 3 and Table I).

\section{Discussion}

The identification of biochemical defects in mucus glycoprotein have been suggested to play a pathophysiologic relevant role in CF lung disease. Although evidence to support this claim remains controversial, such defects have been hypothesized to potentially enhance the ability of bacteria to colonize the CF airways. The fundamental hypothesis of intracellular glycoprotein processing defects stems from previous studies which have demonstrated an altered $\mathrm{pH}$ within golgi compartments of $\mathrm{CF}$ as compared with non-CF cells. In this model, defective CFTR is thought to hinder the acidification of the golgi by a $\mathrm{H}^{+}$ATPase through an increased electrochemical gradient brought about by the lack of CFTR mediated $\mathrm{Cl}^{-}$flow into this vesicular compartment. This increase in $\mathrm{pH}$ is thought to decrease the activity of golgi modifying enzymes such as sialyltransferases which intern provide more assessable sites for sulfation. Hence, the extent of sulfation provides a useful marker for evaluation of intracellular processing defects in glycoprotein such as mucin.

Previous studies evaluating both native and explant produced mucus from $\mathrm{CF}$ and chronic bronchitic patients have compared the extent of mucus sulfation as an endpoint for glycoprotein processing defects. Several studies have reported a 2-3-fold higher level of sulfation together with deceased levels of sialylation in CF airway mucus (26) while others have found no data to support this claim (30). The etiology of differences reported between laboratories presently remains unexplained. We hypothesized that these discrepancies in the literature may be due to differences in CF genotype. Hence, using the level of mucous sulfation as a surrogate endpoint for intracellular glycoprotein processing defects, we sought to perform a comprehensive survey of mucus glycoprotein sulfation from 13 independent $\mathrm{CF}$ samples encompassing seven different mutant CFTR alleles. The human bronchial xenograft was chosen as the model of choice for several reasons including: $(a)$ the absence of secondary effects caused by chronic bacterial infection, $(b)$ its in vivo relevance as a differentiated mucociliary airway epithelium, and $(c)$ the ability to generate genetically defined $\mathrm{CF}$ and non-CF airway epithelium.

The effect of airway remodeling (i.e., goblet cell hyperplasia) due to chronic bacterial infection in CF has provided the largest debated obstacle in evaluating the properties of secreted mucin and may be responsible for many of the conflicting reports evaluating primary defects. Such secondary effects of infection are thought to effect the properties of secreted and membrane bound glycoproteins. To this end, we hypothesized that culturing of CF primary airway epithelial progenitors followed by regeneration of an intact fully differentiated epithelium might provide a more "normal" distribution of airway epithelial cells. In support of this hypothesis is a recently reported study which evaluated the clonal expansion of progenitor cell clones in human bronchial xenografts using retroviral histochemical markers (33). This study, which used in vitro retrovirally infected primary human airway epithelial cells to reconstitute human bronchial xenografts, found that clones composed of goblet cells alone were absent from the reconstituted epithelium. Although these findings do not discount the possibility that goblet cells may be capable of replicating in vivo, these studies demonstrate that goblet cells are not capable of proliferating as progenitor cells in vitro under the conditions described in the present study. Hence we hypothesized that the higher percentage of goblet cells in the initial population of isolated epithelial cells would not contribute to progenitor cells which expand in vivo within xenograft epithelium. This hypothesis assumes that, in the absence of infection, CF airway epithelial progenitor cells would give rise to normal airway architecture. To test this hypothesis, we evaluated the percentage of goblet cells within fully differentiated CF and non-CF xenografts using morphologic techniques of histochemical staining. These studies demonstrated no statistically significant difference in the percentage of alcian blue positive goblet cells between $\mathrm{CF}$ and non-CF xenografts. Such findings support the hypothesis that goblet cell hyperplasia in $\mathrm{CF}$ is an environmentally phenomena stimulated by chronic bacterial infection and not a primary defect caused by defective CFTR function. Additionally, the fact that the total yields of $\left[{ }^{3} \mathrm{H}\right]$ glucosamine labeled large molecular weight purified mucin were not statistically different between $\mathrm{CF}$ and non-CF xenografts substantiates findings which demonstrate a similar abundance of goblet cell (data not shown). These results support the utility of the xenograft model system for studying primary defects in mucus not hindered by secondary effects of infected airways.

Large molecular weight radiolabeled mucus glycoprotein was purified through two rounds of denaturing gel-filtration. As an indicator of mucous processing defect, the extent of radiolabeled ${ }^{35} \mathrm{~S}$ incorporation was compared as the ration to $\left[{ }^{3} \mathrm{H}\right]$ glucosamine 
between 13 paired $\mathrm{CF}$ and non-CF control tissues. Of the seven different genotypes analyzed, CF xenografts demonstrated a $1.7 \pm 0.18$-fold higher $(n=13, P<0.026)$ level of sulfation as compared with non-CF controls. These data substantiate the findings by other investigators which have demonstrated from both in vivo bronchial secretion and in vitro explants a 2-3fold higher level of sulfation. However, further classification of mucous sulfation patterns with respect to 26 screened genotypes demonstrated two categories of CF samples. The first of these categories included CF samples with defined genotypes including $[\Delta \mathrm{F} 508 / \Delta \mathrm{F} 508(n=4) ; \Delta \mathrm{F} 508 / 1717(n=2) ; \Delta \mathrm{F} 508 / 621$ $(n=2)$; G542X/G551D $(n=1) ; \Delta$ F508/G542X $(n=1)]$. No differences in the level of sulfation were seen within these genotypes which cumulatively demonstrated a mean increase in the ${ }^{35} \mathrm{~S} /\left[{ }^{3} \mathrm{H}\right]$ glucosamine ratio of $2.0 \pm 0.15$-fold $(n=10, P<$ 0.004 ). Interestingly, the CF samples which did not demonstrate an increase in sulfation had one unidentified allele [ $\Delta$ F508/unknown $(n=2)$ and G551D/unknown $(n=1)]$. This genotype grouping may in part explain some of the discrepancies in studying sialylation and sulfation in CF secreted mucus in the literature. All CF patients where clinically diagnosed with CF and received lung transplantation as therapy. Several clinical aspects, including age at which transplantation was performed and sweat chlorides, were compared with gain insight into the severity of disease and extent of glycoprotein processing defects. No correlation with the extent of mucous sulfation was seen with either of these two criteria. Furthermore, the extent of lung disease in all CF patients was classified as severe and implies that sulfation of mucus glycoprotein may not be pathophysiologically significant in the progression of lung disease.

The variability in mucous sulfation found between two genotypically defined groups of CF patients at present remains unexplained. However, two current hypotheses are consistent with the findings in this report. First, because of the small numbers of patients with undefined mutant allele(s) which showed no increase in sulfation, these results may be due to variability within the CF population potentially caused by modifying genes. In support of this argument is the one $\Delta F 508 / \Delta F 508$ patient which showed no increase in the level of mucous sulfation (Table I). This finding which demonstrates some level of variability within a defined genotype group, suggests that factor(s) not related to CFTR function may affect mucous sulfation. These factors could simply result from variability within the xenograft model system or may implicate the involvement of other genes in mucus glycoprotein processing. A second more interesting speculation may be that an as yet unidentified mutant allele(s), in the patients with partially defined genotypes, provides some level of functional intracellular CFTR capable of facilitating normal mucus glycoprotein processing. This undefined mutant allele was not found within a comprehensive screen of the 26 common CF genotypes. Despite the cause of variability in mucous sulfation between $\mathrm{CF}$ patients, these studies support previous findings which implicate CFTR functional involvement in mucus glycoprotein processing. The correlation of this defect with CF genotype has provided a more comprehensive look at the complexities by which CFTR may effect this potentially pathophysiologic process.

\section{Acknowledgments}

We greatly acknowledge the assistance of the University of Pennsylvania Molecular Diagnostic laboratory in the genotyping of CF and non$\mathrm{CF}$ tissues.
This work was supported by center grants National Institute of Diabetes and Digestive Diseases (NIDDK) 47757 P30 pilot (J. F. Engelhardt) and NIDDK DK-49136 (J. F. Engelhardt), and the Cystic Fibrosis Foundation 2130 (J. F. Englehardt) at the Institute for Human Gene Therapy, University of Pennsylvania.

\section{References}

1. Boat, T. F., M. J. Welsh, and A. L. Beaudet. 1989. Cystic fibrosis. In The Metabolic Basis of Inherited Disease II, 6th edition. C. R. Scriver, A. L. Beaudet, W. S. Sly, D. Valle. McGrawHill, NY. 2649-2680.

2. Taussig, L. M. 1984. An overview. In Cystic Fibrosis. L. M. Taussig, editor. Theim-Stratton, NY. 1-9.

3. Riordan, J. M., J. M. Rommens, B. Kerem, N. Alon, R. Rozmahel, Z. Grzelczak, J. Zielenski, S. Lok, N. Plavsic, J. L. Chou, et al. 1989. Identification of the cystic fibrosis gene: cloning and characterization of complementary DNA. Science (Wash. DC). 245:1066-1073.

4. Rommens, J. M., M. C. Ianuzzi, B. Kerem, M. L. Drumm, G. Melmer, M Dean, R. Rozmahel, J. L. Cole, D. Kennedy, N. Hidaka, et al. 1989. Identification of the cystic fibrosis gene: chromosome walking and jumping. Science (Wash. DC). 245:1059-1065.

5. Kerem, B., J. M. Rommens, J. A. Buchanan, D. Markiewicz, T. K. Cox, A. Chakravarti, M. Buchwald, and L. C. Tsui. 1989. Identification of the cystic fibrosis gene: genetic analysis. Science (Wash. DC). 245:1073-1080.

6. Rosenfeld, M. A., K. Yoshimura, B. C. Trapnell, K. Yoneyama, E. R. Rosenthal, W. Daleman, M. Fukayama, J. Bargon, L. E. Stier, L. StratfordPerricaudet, M. Perricaudet, W. B. Guggino, A. Pavirani, J. P. Lecocq, and R. G. Crystal. 1992. In vivo transfer of the human cystic fibrosis transmembrane conductance regulator gene to the airway epithelium. Cell. 68:143-155.

7. Engelhardt, J. F., Y. Yang, L. D. Stratford-Perricaudet, E. D. Allen, K Kozarsky, M. Perricaudet, J. R. Yankaskas, and J. M. Wilson. 1993. Direct gene transfer of human CFTR into human bronchial epithelia of xenografts with E1deleted adenoviruses. Nat. Genet. 4:27-33.

8. Zabner, J., D. M. Petersen, A. P. Puga, S. M. Graham, L. A. Couture, L. D. Keyes, M. J. Lukason, J. A. St. George, R. J. Gregory, A. E. Smith, and M. J. Welsh. 1994. Safety and efficacy of repetitive adenovirus-mediated transfer of CFTR cDNA to airway epithelia of primates and cotton rats. Nat. Genet. 6:7583.

9. Zabner, J., L. A. Couture, R. J. Gregory, S. M. Graham, A. E. Smith, and M. J. Welsh. 1993. Adenovirus-mediated gene transfer transiently corrects the chloride transport defect in nasal epithelia of patients with cystic fibrosis. Cell. 75:207-216.

10. Wilson, J. M., J. F. Engelhardt, M. Grossman, R. H. Simon, and Y. Yang. 1994. Gene therapy of cystic fibrosis lung disease using E1 deleted adenoviruses: a phase I trial. Human Gene Therapy. 5:501-519.

11. Boucher, R. C., M. R. Knowles, L. G. Johnson, J. C. Olsen, R. Pickles, J. M. Wilson, J. F. Engelhardt, Y. Yang, and M. Grossman. 1994. Gene therapy for Cystic Fibrosis Using E1-Deleted Adenovirus: A Phase I Trial in the Nasal Cavity. Human Gene Therapy. 5:615-639.

12. Boucher, R. C., M. J. Stutts, M. R. Knowles, L. Cantley, and J. T. Gatzy. 1986. $\mathrm{Na}+$ transport in cystic fibrosis respiratory epithelia. Abnormal basal rate and response to adenylate cyclaseactivation. J. Clin. Invest. 78:1245-1252.

13. Frizzell, R. A., M. Field, and S. G. Schultz. 1979. Sodium-coupled chloride transport by epithelial tissues. Am. J. Physiol. 236:F1-F8.

14. Li, M., J. D. McCann, C. M. Liedtke, A. C. Nairn, P. Greengard, and M. J. Welsh. 1988. Cyclic AMP-dependent protein kinase opens chloride channels in normal but not cystic fibrosis airway epithelium. Nature (Lond.). 331:358360

15. Widdicombe, J. H. 1991. Physiology of airway epithelium. In Airway Epithelium: Lung Biology in Health and Disease. S. G. Farmer and D. W. P. Hay, editors. 55:41-64. Marcel Dekker, New York.

16. Quinton, P. M. 1994. Viscosity versus composition in airway pathology. Am. J. Resp. Crit. Care Med. 149:6-7.

17. Govan, J. R., and J. W. Nelson. 1993. Microbiology of cystic fibrosis lung infections: themes and issues. J. R. Soc. Med. 20:11-18.

18. Prince, A. 1992. Adhesions and receptors of Pseudomonas aeruginosa associated with infection of the respiratory tract. Microbiol. Pathogenesis. 13:251-260.

19. Sajjan, U., J. Reisman, P. Doig, R. T. Irvin, G. Forstner, and J. Forstner. 1992. Binding of nonmucoid pseudomonas aeruginosa to normal human intestinal mucin and respiratory mucin from patients with cystic fibrosis. J. Clin. Invest. 89:657-665.

20. Zach, M. S. 1990. Lung disease in cystic fibrosis-an updated concept. Pediatric Pulmonol. 8:188-202.

21.Al-Awqati, Q., J. Barasch, and D. Landry. 1992. Chloride channels of intracellular organelles and their potential role in cystic fibrosis. J. Exp. Biol. 172:245-266. 
22. Barasch, J., B. Kiss, A. Prince, L. Saiman, D. Gruenert, and Q. Al-Awqati. 1991. Defective acidification of intracellular organelles in cystic fibrosis. Nature (Lond.). 352:70-73.

23. Bradbury, N. A., T. Jilling, G. Berta, E. J. Sorscher, R. J. Bridges, and K. L. Kirk. 1992. Regulation of Plasma Membrane Recycling by CFTR. Science (Wash. DC). 256:530-532.

24. Bradbury, N. A., T. Jilling, K. L. Kirk, and R. J. Bridges. 1992. Regulated endocytosis in a chloride secretory epithelial cell line. Am. J. Physiol.: Cell. Physiol. 262:C752-C759.

25. Boat, T. F., and P. W. Cheng. 1980. Biochemistry of airway mucus secretions. Fed. Proc. 39:3067-3074.

26. Boat, T. F., P. W. Cheng, R. N. Lyer, D. M. Carlson, and I. Polony. 1976. Human respiratory tract secretions: mucous glycoproteins of nonpurulent tracheobronchial secretions, and sputum of patients with bronchitis and cystic fibrosis. Arch. Biochem. Biophys. 177:95-104.

27. Roussel, P., G. Lamblin, P. Degand, E. Walker-Nasir, and R. W. Jeanloz. 1975. Heterogeneity of the carbohydrate chains of sulfated bronchial glycoproteins isolated from a patient suffering from cystic fibrosis. J. Biol. Chem. 250:21142122.

28. Cheng, P. W., J. M. Sherman, T. F. Boat and M. Bruce. 1981. Quantitation of Radiolabeled Mucous Glycoproteins Secreted by Tracheal Explants. Anal. Biochem. 117:301-306.

29. Rose, M. C. 1988. Epithelial Mucous Glycoproteins and Cystic Fibrosis. Horm. Metabol. Res. (Review). 20:601-608.

30. Gupta, R., and N. Jentoft. 1992. The structure of tracheobronchial Mucins from cystic fibrosis and control patients. J. Biol. Chem. 267:3160-3167.

31. Engelhardt, J. F., J. R. Yankaskas, and J. M. Wilson. 1992. In vivo retroviral gene transfer into humanbronchial epithelia of xenografts. J. Clin. Invest. 90:2598-2607.

32. Goldman, M. J., Y. Yang, and J. M. Wilson. 1995. Gene Therapy in a xenograft model of cystic fibrosis lung corrects chloride transport more effectively than the sodium defect. Nat. Genet. 9:126-131.

33. Engelhardt, J. F., H. Schlossberg, J. R. Yankaskas, and L. Dudus. 1995. Novel mechanisms of submucosal gland development and morphogenesis in the adult human airway. Development (Camb.). 121:2031-2046. 